\title{
Leadership Development through Workplace Learning in Malaysian Organizations
}

\author{
Nor Wahiza Abdul Wahat ${ }^{1}$, Steven Eric Krauss ${ }^{1} \&$ Jamilah Othman $^{2}$ \\ ${ }^{1}$ Institute for Social Science Studies, Universiti Putra Malaysia, Malaysia \\ ${ }^{2}$ Department of Professional Development and Continuing Education, Faculty of Educational Studies, Universiti \\ Putra Malaysia, Malaysia \\ Correspondence: Nor Wahiza Abdul Wahat, Institute for Social Science Studies, Universiti Putra Malaysia, \\ Malaysia. E-mail: norwahiza@gmail.com
}

Received: January 9, 2013 Accepted: March 20, 2013 Online Published: April 27, 2013

doi:10.5539/ass.v9n5p298 URL: http://dx.doi.org/10.5539/ass.v9n5p298

\begin{abstract}
This paper focuses on leadership development of successful leaders via informal workplace learning in several Malaysian organizations. Leadership development, which involves a life-long process of learning beginning from childhood and one's early educational experiences, often continues with experiential learning in the workplace. Though many previous studies have explored leadership development via formal programmes in workplaces, there have been limited studies that narrate the contribution of informal learning in workplaces. Hence, we conducted in-depth interviews with five top management team members (TMT) of organizations in the Malaysian higher education, banking and service industries to understand their leadership development experiences. The results included the overarching theme that leadership development should never be separated from organizational priorities, as leaders are the ones who define an organization's future. The three sub-themes which emerged in relation to leadership development in the context of workplace learning were: (a) the role of informal mentoring in leadership development; (b) observation and reflection during leadership development; and (c) developmental, challenging assignments in leadership development. The findings are presented along with implications for leadership development research and practices in organizations.
\end{abstract}

Keywords: leadership development, work place learning, qualitative, informal mentoring, observation, reflection

\section{Introduction}

\subsection{Leadership Development and Continuous Learning}

"The primary source of learning to lead, to the extent that leadership can be learned, is experience. The role played by training and other formal programs is relatively modest in comparison to other kinds of (on-the-job) experiences" - McCall (2004).

Leadership development is defined as expanding the collective capacity of organizational members to engage effectively in leadership roles and processes (McCauley, et.al., 1998). It enables groups of people to work together, solve problems and use their seen and unseen capacities to face challenges (Keys \& Wolfe, 1988; Hooijberg, Bullis \& Hunt, 1999). Literatures have widely reported the important stages of leadership development. It includes assimilation of values and experiences in one's life such as those during childhood, formal education and work experiences (Popper, 2005; Avolio \& Luthans, 2005, Avolio, 1999; Kuhnert \& Russell, 1990). Hence, it is clear that leaders are not born nor are they significantly shaped from book readings. Leaders are mostly formed through authentic moments of leadership development.

Childhood and educational experiences are not the only important phases in developing leaders. Leadership development is a lifelong and continuous learning process that revolves around formal and informal learning at individuals' workplaces, where the best leadership development experiences are usually gained from real business and organizational life. Even though leadership development could be considered as a form of self-development, organizational activities significantly contribute to developing individuals' potential towards dynamism that can lead to organizational outcomes such as a higher performance culture, better decision-making, attracting and retaining staff, as well as the ability to mobilize resources. It is the hands-on, slippery experiences 
with organizational culture, politics, and phases of success and turmoil that help individuals refine their strategies, skills and abilities as effective leaders within their work contexts. Recent research by Ema Central and Catapult involving leaders from 70 organizations indicated that challenging situations such as economic recession made them review their businesses more strategically, helped them to manage their moods and developed their ability to remain calm under great stress (Baker, 2010). Well-known organizations that practice action and experiential learning for the leadership development of their employees include companies such as Hewlett-Packard, GE, IKEA, Motorola and Coca Cola (Smith, 2001). Thus, much evidence exists to support the idea that experiential learning via significant events in organizations can serve as an important tool to sharpen leaders' knowledge, skills and attitudes.

Although literatures have reported the benefits of workplace learning, there have been limited studies narrating experiential learning in terms of leadership development of successful leaders, particularly those in Malaysian organizations. In addition, few studies have looked at leadership development through the integration of experiential learning theory (ELT) $($ Kolb, 1984) and the motivation-based theory of skills acquisition (Kanfer \& Ackerman, 1989). With this backdrop, the current study aimed to understand the essence of experiential and workplace learning in the context of the leadership development process among top management team members from several public, government-linked (GLCs) and private organizations in Malaysia. Specifically, we set out to explore in what ways successful leaders attribute their development of leadership skills, knowledge and attitude to workplace learning. The paper is organized into several sections covering theories and past research related to leadership development through workplace learning, followed by methodology, and results of the qualitative interviews. The paper concludes with a discussion on the implications of the findings and recommendations for future research and practice. It is believed that the findings can facilitate efforts to develop and shape future leaders.

\subsection{Theorizing Leadership Development through Workplace Learning}

Initially, workplace learning was defined as a forced task in a social context (Resnick, 1987). Being closely associated with training and development, organizational development and career development to improve individual, group and organizational effectiveness (McLagan, 1989), recent definitions of workplace learning have focused not only on the needs of individual development, but also on the role of management in its delivery and success (Rothwell \& Sredl, 1992). Billett (2008) defined workplace learning as the process in and through which professionals interact with the social experiences they encounter in the workplace. Three important highlights have been discussed in the broader perspective of workplace learning. First, workplace learning includes both learning activities in the workplace and learner-oriented activities (Marsick, 1987). Second, organization is both a working and learning place (Matthews, 1999). And third, workplace learning experiences emerge from both interpersonal and contextual factors that focus on social context (Illeria, 2004). In relation to leadership, Gunter and Ribbins (2002) argued that leadership development is not merely about the acquisition of skills, techniques and capacities, but that it can only be understood through the gathering of professional experiences from within contextualized settings. Taking these aspects into consideration, Moon and $\mathrm{Na}$ (2009) defined workplace learning as a process in which individuals, teams, and organizations obtain knowledge, skills and attitudes according to their continuous interactions with each other or within the context of solving work-related problems and improving performance.

Workplace learning includes formal, informal and incidental learning (Marsick \& Watkins, 2001). The formal learning refers to various leadership training programs and strategies such as 360 degree feedback, coaching, spread learning and personal development planning. On the other hand, informal learning refers to a wide variety of spontaneous, unofficial, and impromptu ways on how to perform one's job. Informal learning is also a personalized form of codified, procedural and process knowledge acquired implicitly and almost spontaneously from a learning context, which allows an individual to perform competently in a situation. The process of socialization through observation, interaction, and involvement in various organizational activities provide the means to build an individual's knowledge, values, skills and credibility as a leader (Eraut, 2000). By offering employees every chance to be all that they can be, informal learning comprises nearly $90 \%$ of adults' learning in organizations (Kim, Collins, Hagedorn, Williamson \& Chapman, 2005; Cross, 2006; Merriam, Caffarella \& Baumgartner, 2007).

The current study focused on the contribution of informal and incidental learning to leadership development, which we believed to be relevant due to the growing belief that informal, on-the-job work experience is an effective way to develop leaders and leadership skills. According to McCall $(2004,127)$, "the primary source of learning to lead, to the extent that leadership can be learned, is experience. The role played by training and other formal programs is relatively modest compared to other types of on-the-job training experiences." 
Combined efforts by both individuals and organizations are required to mould employees into leaders. Such efforts do not solely fall entirely within the purview of self-development or organizational responsibility, but rather the interaction between them required to facilitate leadership development indicates that experience is an important element in the process. Such interaction could also occur through informal, experiential learning. Thus, an appropriate theoretical framework to explain successful leadership development through workplace learning is the integration of experiential learning theory (ELT) by Kolb (1984) and the motivation-based theory of skills acquisition (Kanfer \& Ackerman, 1989). Experiential learning theory introduced by Kolb (1984) has been one of the foremost theories used in studies on managers' learning experience (Kayes, 2002; Yamazaki \& Kayes, 2004). Kolb (1984) defines experiential learning as the process whereby knowledge is created through the transformation of experience. In adapting to one's position and situation, experiential learning theory emphasizes the central role of experience in the process of learning. Learning itself is regarded as an integration of thinking, feeling, perceiving and behaving. The ELT addresses two processes: (1) grasping experience; and (2) transforming experience. In grasping experience, individuals learn through either concrete or abstract conceptualization experiences. The modes of learning from experience are usually based on one of these two. Concrete conceptualization usually refers to tangible and immediately felt qualities of experiences, while abstract conceptualization evolves around symbolic interpretation of individual experiences. In the process of transforming experience, individuals learn via reflective observation or active experimentation modes. From reflective observation, learning occurs when individuals transform their observations through internal processing. Meanwhile, via active experimentation individuals learn when transforming occurs through actual manipulation of the external world.

Figure 1 illustrates the experiential learning cycle consisting of all the learning modes. The cycle illustrates how observation and reflection emerge from immediate concrete experience, and how the experience is assimilated into abstract conceptualization. The abstract conceptualization, in turn, is formed into active experimentation with the real world. The cycle of learning is completed by active experimentation and the beginning of newly created experiences (Kolb, 1984; Kolb \& Kolb, 2005). The motivation-based theory of skills acquisition by Kanfer and Ackerman (1989) proposes that challenging experiences faced by individuals allow growth in knowledge and skills. When dealing with difficult tasks and assignments, individuals are motivated to put in extra effort to complete the tasks. According to Ohlott (2004), developmentally challenging experiences may include managing unfamiliar responsibilities, creating change, bearing high levels of responsibility, working across boundaries and managing diversity. Through the need to complete assignments, individuals are moved to try out new behaviors, explore new ideas, reframe their ways of thinking, and establish broader networks. Hence, they are more ready, knowledgeable and skillful to face future tasks.

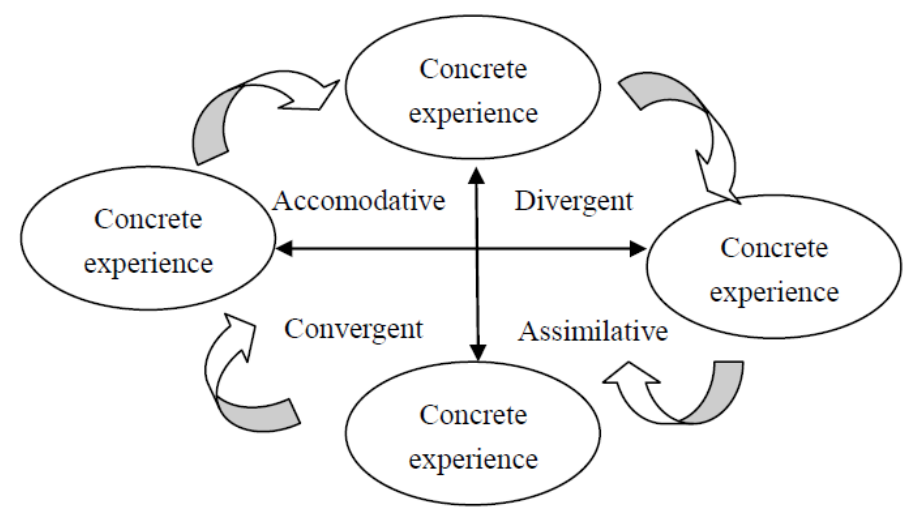

Figure 1. Experiential learning cycle

Source: http://www.learningfromexperience.com

In discussing the effectiveness of developmentally challenging experiences in developing leaders, DeRue and Wellman (2009) supported the importance of feedback from superiors in the developmental process. Their study showed that individuals' who had access to feedback from their supervisors were less likely to experience diminishing returns in leadership development skills as compared to those who did not get feedback on their performance in handling challenging tasks. Thus, another type of experience that is essential to help grow and develop leaders is the leader-subordinate relationship experience. Mentoring, therefore, be it formal or informal, can be one of the ways to provide effective workplace learning experience. Informal mentoring as a form of 
workplace learning occurs when an employee seeks out help on certain problems from superiors. Mentoring is most effective when superiors are willing to spend their time to transfer skills and knowledge, are open enough to take risks, are willing to share their experiences and are willing to help. As an outcome, the mentee benefits by having more understanding of the organization's policies and environment, improved self-organization and more opportunities to network (Dymock, 1999).

\section{Method}

\subsection{Study Informants}

This study adopted a qualitative research design. Utilization of a qualitative approach allowed us to obtain a rich, subjective perspective in understanding the leadership development experiences of top management team members. In-depth investigation of the informants' views and experiences allowed us to understand the essence of experiential and workplace learning in developing leadership skills, knowledge and attitude. The descriptions provided by the leaders on their personal experiences in relation to their own leadership development aimed to help us understand, explain and shape strategies for leadership development through workplace learning for the benefit of future leaders.

A list of high ranking leaders was identified and purposeful sampling was conducted. The main criterion to choose the informants was their positions as members of the top management teams (TMTs) in each of their organizations. A total of five informants were involved. This study involved two female and three male leaders from public, government-link (GLCs) and private organizations in Malaysia. Each of them served in the top management teams (TMT) of their respective organizations. Top management teams refer to managerial elites, who occupy formally defined positions of authority. They are usually powerful actors in organizations holding strategic positions such as members of the board of directors, or executive committees (Pettigrew, 1992). TMTs were also defined as the relatively small group of the most influential executives in organizations, i.e., the top three to ten executives (Finkelstein \& Hambrick, 1996). In this study, two of the respondents were vice chancellor and deputy vice chancellor of a public university, one was a Group Chief Executive Officer of a financial institution, one was a Chief Executive Officer of a service organization and another one was a senate member of a public university.

It is worth noting that the informants who participated in this study were from different organizational settings and industries. Nevertheless, it was believed that such variance would not negatively affect the results of the study. This is based on the belief that the distinct ways and paths to leadership development that differ from one organizational context to another usually erode due to homogenization of leadership and management (Bolden et al., 2008; Kempster, 2009; Pinnington, 2011).

\subsection{Data Collection}

Semi-structured in-depth interviews were used to collect the data for the study. We used an interview guide to ensure that all questions asked during the in-depth sessions were focused on the objectives of the study. The questions included in the interview guide were related to their leadership development experiences since the beginning of their entry into organizational settings until the time they achieved their current leadership positions. One of the questions asked was 'was there anyone whom you have looked upon as a role model or whom have guided you throughout your working years?'

Each interview lasted for about one and a half to two hours. The sessions were recorded using a digital recorder and later on transcribed into verbatim transcripts. Permission was sought from the informants prior to the interviews. Since videotaped sessions could be deemed invasive, the in-depth interviews were recorded using digital audio recorders. The use of digital recorders facilitated data management and transcription of data from the verbatim transcripts. Beside the recording and utilization of the interview guide, we also made field notes which facilitated understanding of the informants' experiences in a more unobtrusive manner.

Several guidelines were observed in conducting the study: firstly, we played the role of research instrument throughout data collection when we interacted within the research context, chose the appropriate data collection techniques, were sensitive to non-verbal communication during the interviews, and continuously processed and analyzed the data (Guba \& Lincoln, 1981). Secondly, we met with the informants to gain a deep understanding of the investigated issue. Thirdly, the results were reported in a rich, descriptive manner based on the transcribed interviews with the informants.

\subsection{Data Analysis}

Cross-case analysis was conducted concurrently with data collection. Data analysis was conducted using the constant comparative method and included the following four stages: (1) comparing incidents applicable to each 
category, (2) integrating categories and their properties, (3) delimiting the theory, and (4) writing the theory (Lincoln \& Guba, 1985). We initially read the verbatim transcripts several times, identified the incidents, and made simultaneous comparison of the incidents. The compared incidents were then recorded, classified and compared across categories. We continuously conducted constant comparison on the data and focused on discovery of new patterns through coding them into meaningful categories and themes. The categories and themes were labeled with numbers. For example, the theme 'leadership development via workplace learning' was labeled as 001. Subsequently, all the recurring phrases or sentences supporting the themes were highlighted and marked with comments using Microsoft Word. All the data were saved into a Microsoft word file named 'themes'.

Also, in the process of categorization as proposed by Dey (1993), we read the verbatim transcripts several times to familiarize ourselves with the data, build, changed or sometimes even discarded categories, and avoided category overlaps by constantly referring to the research questions, related theories on leadership development through workplace learning, intuition and/or previous knowledge. The whole process of constant comparative analysis thus involved refinement, categorization and recategorization. This process saved us from jumping into premature conclusions and enabled them to manage voluminous data more systematically (Merriam, 1998).

The validity and trustworthiness of the findings were ensured through investigator triangulation, where multiple researchers are involved in the process. We collected the data, analysed it independently and compared our findings (Patton, 2002). Another strategy used was an audit trail, where we recorded steps taken during the study, including how data was collected, how we derived categories, and how decisions were made regarding certain questions, reflections, ideas and issues. We also practiced tolerance, alertness, sensitivity, and good communication skills throughout the research process.

\section{Results and Discussion}

The constant comparative method utilized in the data analysis resulted in the generation of three themes: (1) leadership development through informal mentoring, (2) leadership development through reflection and observation, and (3) leadership development through challenging assignments. All generated themes highlight what the leaders went through during their respective careers, and how it helped them develop their leadership skills, knowledge and attitude. The learning experiences that enhanced their leadership were more informal than formal. The results are in line with Moon and Na's (2009) definition of workplace learning, which equates individuals' interactions in the workplace to a process that allows them to learn, develop and operate effectively in their organizations. Spontaneous and informal learning through observations, interactions and activities helps them develop their leadership confidence, competence, values and skills.

\subsection{Leadership Development through Informal Mentoring}

Mentoring provided a clearer picture for the younger leaders on appropriate strategies that could be adopted to ensure continuous excellence in performance. When mentors were willing to share their opinion, experience and the way they feel about certain issues, it allowed the younger ones to climb the organizational ladder more confidently. It also helped them to identify the right ladders to climb. The following statement by one of the leaders echoed Dymock's (1999) proposition that mentees benefitted from accessible mentors when they had the chance to understand more about organizational policies and culture, improve self-organization and gain more networking opportunities. In one phase of his career, a particular leader learned from his superior that meeting people and demonstrating excellence is crucial. He also learned the importance of practicing open door policies to encourage the flow of new ideas:

You have to be on track (in terms of) meeting people and indicating that you are on the right track. I learnt this from my chairman during graduate program. He never said that your answer is wrong. It makes you feel so good. Encouraging moment... I think that's the way too. So, I've used this principle whenever we had meetings. When you get out of the door, you don't say that idea is lousy because the idea comes from somebody in lower position. If the idea is good, why not?

Another informant, a vice chancellor from a public university, also acknowledged that the feasibility to learn directly from his two previous vice chancellors helped shape his own way of dealing with issues in the university. His leadership development experience during the eras of his predecessors made him both cautious and nurtured in him the desire to do everything 'the right way':

When I observed the earlier vice chancellor, he was such a fantastic leader. What he did, now you can see the result. He was doing the right things, changing the shape of the university. I think I have the privilege of inheriting the two leadership traits from two previous vice chancellors. The latter was a very cautious 
man. He wanted to do everything right. The former wanted to do the right things. I think I am both.

Another informant from the service industry illustrated his direct informal workplace training with two entrepreneurs as a key input to his career development. The experiences with these two entrepreneurs sculpted him to become a results-oriented leader:

I think what simply shaped what I am today, basically was my training with two entrepreneurs. One is known for his leadership style, his own unique way of managing. Not an easy boss to work with, not an easy person... very task driven. Even people quoted him as a slave master. So, basically we had a very results-orientated kind of training. Another one is one of our friends here. The first one molded me in such as way that everybody knows that I am his protégé.

The above exemplars illustrate how the informants' socialization and collaborative partnership through assignments with their informal mentors helped shape their ideals about how leaders should be along the path to becoming leaders themselves. The leadership development lessons from earlier observations and experiences guided the informants in the performance of their leadership principles and behaviors.

\subsection{Leadership Development through Observation and Reflection}

Observation and reflection in leadership development, as described by our informants, parallels with experiential learning theory (Kolb, 1984), by positioning the central role of experience in the process of learning. The following informant described the observations and reflections he made on the leadership style of a research team leader during an opportunity to collaborate in a study with Japanese counterparts. The process of knowledge transformation through his experience, involving the internal processes of thinking, feeling, perceiving and behaving is clearly narrated below:

I have been involved in a study under the Hitachi Corporation. I was in Japan as the counterpart and joined an associate professor, the lecturer, the $\mathrm{PhD}$ and master students. The Japanese style was they discussed every question, then they asked is this the right way to ask these questions? What are the expected answers? Then I realized that he has one particular question that has so many answers. So we, we grind out [again] the questions....But during the process, my counterpart, who was the chairman, didn't say anything in terms of making the decision. He was asking the professor, then the associate professor, what you're thinking, then the $\mathrm{PhD}$ students, then the master students and finally he asked me. Then finally he said okay, we have discussed this and the final answer is obvious because all of us contributed. The chairman didn't say, I think I like this or I like that. So, I was very impressed.

The ability to be observant and the capability to reflect on learning moments with other leaders proved to be essential for the informants' own leadership development. Results from the internal process of transforming their learning experiences into perceptions and behaviors guided them in dealing with their work life realities.

\subsection{Leadership Development through Challenging Assignments}

The motivation-based theory of skills acquisition by Kanfer and Ackerman (1989) proposes that challenging experiences faced by individuals allow for growth in their knowledge and skills. When dealing with difficult tasks and assignments, individuals are often motivated to put in extra effort to complete their tasks. According to Ohlott (2004), among the tasks considered developmentally challenging are those involving change creation and high level responsibility. The following informant narrated her developmental experiences as a young lecturer, laboratory leader, deputy dean and in her current position as a Deputy Vice Chancellor. She admitted that all the challenging tasks that she had to undertake while holding her earlier leadership positions were helpful to her in her present capacity. The cumulative experience equipped her with vast knowledge and information on rulings, procedures and other relevant aspects that have allowed her to excel:

I started as a young lecturer. Then I handled the lab. For my section, I was the only one in that area. So, I developed the whole thing about my section. When I became the deputy dean, I had to do many things, even develop rules and regulations for the undergraduates. I was involved in the early part. When I went to the graduate school, I developed the [graduate education] system. So I know finger tips about what was happening. If I'm here and I want some information from the graduate school, I know what's there in the graduate school. I think to be a leader, you have to know what the game is all about, what information is required and you must be in top form in terms of knowledge.

The following informant, a banking group CEO, talked at length about her appreciation of the challenging experiences that she went through during her early days before acquiring her current position. According to her, the crises she dealt with in each of her positions along the way helped prepare her for higher leadership positions. She admitted that her earlier experiences facing a variety of challenges were an important part of that which 
qualifies one to excel and be considered a successful leader. Hence, the initiatives taken to experiment with different behaviors, explore new ideas, reframe arguments and opinions, develop more strategic ways of thinking and establish broader networks to solve crises are essential for successful leadership. Such experiences prepare individuals to be more ready, knowledgeable and skillful in facing future - and more formidable -- tasks as they climb the ladder of leadership responsibility and success:

I have had many situations in my career after thirty over years of crisis. But I always believe that God made me go through this to prepare me for higher job because if you want to sit in this job, you have to have the ability and the resilience to tackle a lot of things. I think I was made and paid to take the bullets. So, if I didn't go through all those bad experiences, I don't think I would be mentally ready to manage this responsibility. Really, honestly speaking I think it's quite a parcel what had got me here. It is part of the journey. Of course there are sometimes situations where people have to walk away if it becomes impossible. But I always tell myself that I will never quit when I'm down. I will only quit when I'm up.

\section{Conclusion and Recommendations}

The essence of workplace learning via informal mentoring, observation and reflection as well as challenging assignments is thus well highlighted in this context of study. The research findings confirmed that there is no best way to teach the art of leadership. Informal mentoring provided our successful leaders with opportunities to learn various leadership principles, attitudes, skills, styles and behaviors from their seniors or supervisors. The ability to observe and reflect on various events and experiences during their years of leadership development appeared to be highly useful and even transformational. Such skills allowed them to assess, evaluate and adopt important leadership qualities suited to their own contexts to ensure effective and efficient practice. Last but not least, difficult but guided assignments challenged and ultimately helped them to maximize their leadership potentials to their full capacity.

Based on the findings, although contextual and limited, the following recommendations are proposed: (1) Top management of organizations could include the essence of the three identified themes within their corporate values training programs. By incorporating a culture of informal mentoring, guided challenging assignments and emphasis on observation and reflection and disseminating these values through various channels including training, the development of future leaders might be more meaningful and impactful. (2) In relation to the first recommendation, we also recommended for organizational management to conduct needs assessment case studies within their organizations in order to identify the missing abovementioned elements within their leadership development efforts and programs. Case studies allow for in-depth understanding of both the outcomes and processes related to leadership development, and provide rich, contextual data that empirical instruments alone often cannot capture. The results of such case studies can help to identify existing strengths and weaknesses of leadership development programs and practices.

\section{References}

Avolio, B. J. (1999). Full leadership development: Building the vital forces in organizations. Thousand Oaks, CA: Sage.

Avolio, B. J. (1999). Full leadership development: building the vital forces in organizations. Thousand Oaks, California: Sage Publications.

Avolio, B. J., \& Luthans, F. (2005). The high impact leader. Moments matter in accelerating authentic leadership development. New York: McGraw-Hill Inc.

Baker, G. (2010). Growing the leader within NZ Business. ABI/INFORM Trade \& Industry, 24(4), 18.

Billett, S. (1995). Workplace learning: Its potential and limitations. Education \& Training, 37(5), 20-27. http://dx.doi.org/10.1108/00400919510089103

Bolden, R., Petrov, G., \& Gosling, J. (2008). Tensions in Higher Education leadership: Towards a multi-level model of leadership practice. Higher Education Quarterly, 62(4), 358-376. http://dx.doi.org/10.1111/j.1468-2273.2008.00398.x

Cross, J. (2006). Informal learning: Rediscovering the natural pathways that inspire innovation and performance. San Francisco: Pfeiffer.

Dey, I. (1993). Qualitative data analysis: A user-friendly guide for social scientists. London: Routledge. http://dx.doi.org/10.4324/9780203412497

Dymock, D. (1999). Blind date: a case study of mentoring as workplace learning. Journal of Workplace Learning, Employee Counselling Today, 11, 312-317. http://dx.doi.org/10.1108/13665629910300496 
Eraut, M. (2000). Non-formal learning, implicit learning and tacit knowledge. In F. Coffield (Ed.), The Necessity of Informal Learning. Policy Press.

Finkelstein, S., \& Hambrick, D. C. (1996). Strategic leadership: Top executives and their effects on organizations. New York: West Publishing Company.

Glaser, B. G. (1978). Theoretical Sensitivity. Mill Valley: Sociology Press.

Gronn, P. (1995). Greatness re-visited: The current obsession with transformational leadership. Leading and Managing, 1(1), 14-27.

Guba, E., \& Lincoln, Y. (1981). Effective evaluation. San Francisco: Jossey-Bass.

Gunter, H., \& Ribbins, P. (2002). Leadership studies in education towards a map of the field. Educational Management Administration Leadership, 30(4), 387-416. http://dx.doi.org/10.1177/0263211X020304003

Hambrick, D. C., \& Mason, P. A. (1984). Upper echelons: The organization as a reflection of its top managers. Academy of Management Review, 9(2), 193-106. Retrieved from http://www.jstor.org/stable/258434

Hooijberg, R., Hunt, J. G., \& Dodge, G. E. (1997). Leadership complexity and development of the Leaderplex model. Journal of Management, 23, 375-408. http://dx.doi.org/10.1177/014920639702300305

Horwitz, R. (2010). Elements of a successful leadership development program. Canadian HR Reporter, 23(5), 18. Retrieved from: http://www.leadership-vancouver.ca/documents/cdnhrreporterarticle_mar2010.pdf

Kanfer, R., \& Ackerman, P. L. (1989). Motivation and cognitive abilities: An integrative/aptitude-treatment interaction approach to skill acquisition. Journal of Applied Psychology, 657-690. Retrieved from: http://thesedominiquebellec.fr/bibliographie/base_articles/Motivation\%20and\%20Cognitive\%20Abilities\% 20An\%20IntegrativeAptitude-Treatment.pdf http://dx.doi.org/10.1037/0021-9010.74.4.657

Kayes, D. C. (2002). Experiential learning and its critics: Preserving the role of experience in management learning and education. Academy of Management Learning and Education, 1(2), 137-149. http://dx.doi.org/10.5465/AMLE.2002.8509336

Kempster, S. (2009). Observing the invisible: Examining the role of observational learning in the development of leadership practice. Journal of Management Development, 28(5), 439-456. http://dx.doi.org/10.1108/02621710910955976

Keys, J. B., \& Wolfe, J. (1988). Management education and development: Current issues and emerging trends. Journal of Management, 16, 307-336. http://dx.doi.org/10.1177/014920639001600205

Kim, K., Collins Hagedorn, M., Williamson, J., \& Chapman, C. (2004). Participation in Adult Education and Lifelong Learning: 2000-01 (NCES 2004-050).

Kolb, D. A. (1984). Experiential learning: Experience as the source of learning and development. New Jersey: Prentice-Hall.

Kuhnert, K. W., \& Russell, C. J. (1990). Theory and practice in the selection and development of organizational leaders. Journal of Management, 16, 595-607. http://dx.doi.org/10.1177/014920639001600305

Marsick, V. J. (1987). New paradigms for learning in the workplace. In V. J. Marsick (Ed.), Learning in the workplace. London: Croom Helm.

Marsick, V. J., \& Watkins, K. J. (2001). Informal and incidental learning. New directions for adult and continuing education, 89, 25-34. http://dx.doi.org/10.1002/ace.5

Matthews, P. (1999). Workplace learning. Developing a holistic model. The learning organization, 6(1), 18-21. http://dx.doi.org/10.1108/09696479910255684

McCall, M. W. (2004). Leadership development through experience. Academy of Management Executive, 18(3), 127-130. http://dx.doi.org/10.5465/AME.2004.14776183

McCauley, C. D., Moxley, R. S., \& Van Velsor, E. (1998). The Handbook for Leadership Development. San Francisco: Jossey-Bass.

McLagan, P. A. (1989). Models for HRD Practice. Training and Development Journal, 49-59.

Merriam, S. B. (1998). Qualitative Research and Case Studies Applications in Education. San Francisco: Jossey-Bass Publications.

Merriam, S. B., Caffarella, R. S., \& Baumgartner, L. M. (2007). Learning in adulthood: A comprehensive guide (3rd ed.). San Francisco: Jossey-Bass. 
Moon. S., \& Na, S. (2009). Psychological and organizational variables associated with workplace learning in small and medium manufacturing businesses in Korea. Asia Pacific Education Review, 10, $327-336$. http://dx.doi.org/10.1007/s12564-009-9040-1

Parsloe, E. (1992). Coaching, Mentoring and Assessing. London: Kogan Page.

Patton, M. Q. (2002). Qualitative Research and Evaluation Methods. Thousand Oaks, CA: Sage Publications.

Pettigrew, A. M. (1992). The character and significance of strategy process research. Strategic Management Journal, 13(Special Issue), 5-16. http://dx.doi.org/10.1002/smj.4250130903

Pinnington, A. H. (2011). Leadership development: Applying the same leadership theories and development practices to different contexts. Leadership, 7(3), 335-365. http://dx.doi.org/10.1177/1742715011407388

Popper, M. (2005). Main principles and practices in leadership development. Leadership and Organizational Development Journal, 26(1), 62-75. http://dx.doi.org/10.1108/01437730510575598

Resnick, L. (1987). Learning in school and out. Educational Researcher, 16(9), 13-20.

Rothwell, W. J., \& Sredl, H. J. (1992). Guide to Workplace Learning and Performance (3rd ed.). HRD Press.

Smith, P. A. C. (2001). Action learning and reflective practice in project environments that are related to leadership development. Management http://dx.doi.org/10.1177/1350507601321003

Wellman, D. S. D. N. (2009). Developing Leaders via Experience: The Role of Developmental Challenge, Learning Orientation, and Feedback Availability. Journal of Applied Psychology, 94(4), 859-875. http://dx.doi.org/10.1037/a0015317

Yamazaki, Y., \& Kayes, D. C. (2004). An experiential approach to cross-cultural learning: A review and integration of competencies for successful expatriate adaptation. Academy of Management Learning \& Education, 3(4), 362-279. http://dx.doi.org/10.5465/AMLE.2004.15112543 